\title{
OBITUARY
}

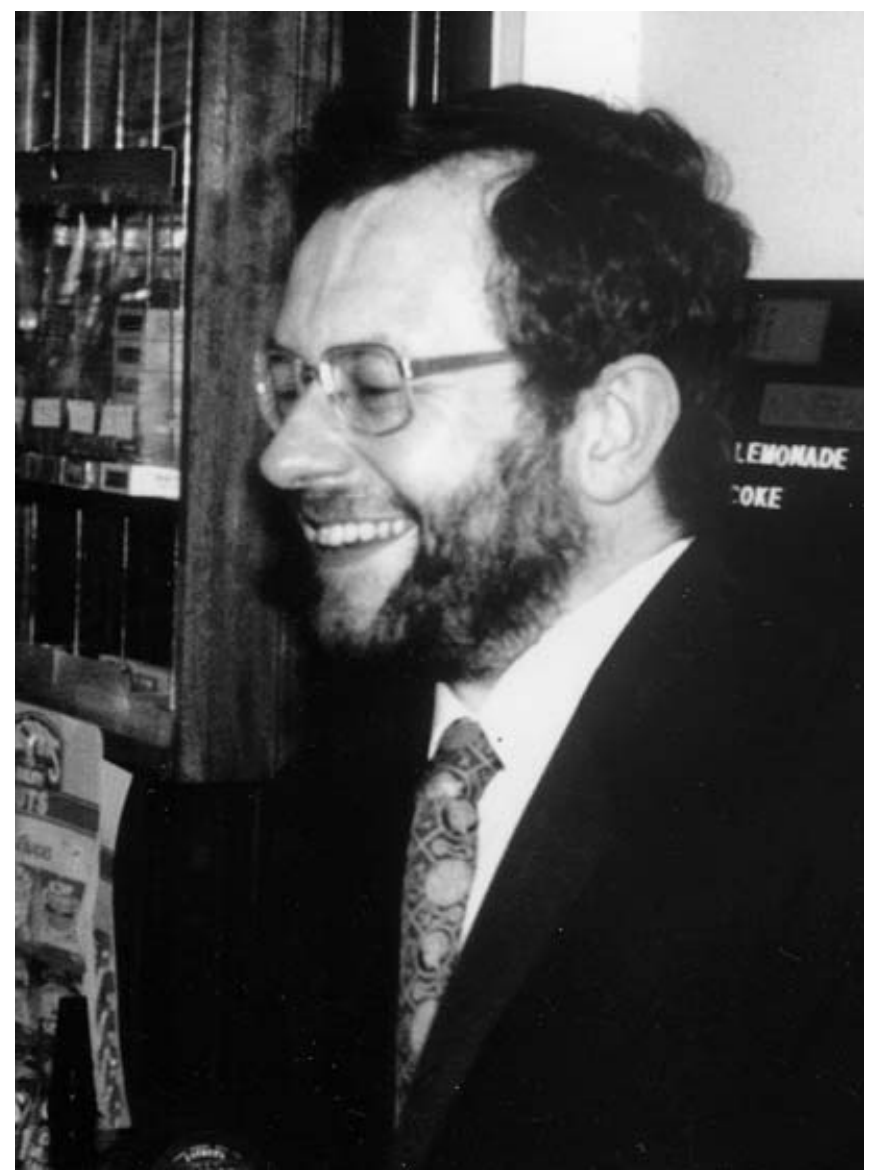

\section{ROBERT WINSTON KEITH ODONI}

(1947-2002)

Born in London on 14 July 1947, Robert Winston Keith Odoni was the eldest of the five children of Walter Anthony and Lois Marie Theresa Odoni. The family name is Italian: grandfather Alfred Odoni had come to England from Switzerland in the 1920s and set up a manufacturing business in Birmingham, later transferring to London. Robert's father continued the business (then making cycle stands) until the 1970s. His mother was from Boulder in Colorado: they had met in America whilst he was on wartime naval service.

After attending a small private primary school, Robert's secondary education was at Queen Elizabeth's Grammar School in Barnet (1958-65). Aged around 14 he informed his careers' master he would like to read chemistry at university. The latter advised his parents that chemistry is "very mathematical these days and his maths is 
not up to it - perhaps he might aspire to become a lab assistant". Rather than being a discouragement, this was taken by Robert as a spur to "get his maths up to it". Thus, in 1965 he went to Exeter University initially to read for a Combined Honours Degree in Chemistry and Mathematics. But from the questions he was asking, it quickly became apparent to his mathematics lecturers that his talents lay in mathematics rather than chemistry, and he transferred to Honours Mathematics after the first year. He became a prize-winning student, the best in his year. "Exeter never had as good an undergraduate in my time" was one authoritative assessment.

From 1968-71 Robert was at Downing College, Cambridge, researching for a $\mathrm{Ph}$.D. in analytic number theory, originally under the supervision of Professor Harold Davenport, FRS, and then, after the latter's death in 1969, under Professor Alan Baker, FRS. A break in supervision like this is a test of the inherent abilities of any research student, but Robert read widely, worked hard, and produced his thesis Asymptotic properties of some number theoretic functions in good order. Accordingly, he graduated Ph.D. (Cantab) in 1972.

After Cambridge, Robert held academic positions in various university mathematics departments. He was Temporary Lecturer at Liverpool for one year (197172) and Research Fellow at Glasgow for the next (1972-73), before moving back to Exeter as Lecturer in Pure Mathematics in 1973. He remained there for 16 years, being promoted to Reader in 1979 and to Professor of Number Theory in 1985 (a Personal Chair). In 1989, he was appointed as Professor of Pure Mathematics at the University of Glasgow, a position which had become available through the retirement, some time before, of another distinguished number-theorist (Robert A. Rankin) from the original 1691 Chair of Mathematics at the university. In 2001, because of ill-health, Robert was compelled to take early retirement from this post (if not from mathematics itself).

Near the end of his third year in Cambridge, Robert had been introduced to Josie Ding. Briefly separated while he went to Liverpool and she attended college in Harlech, they were married in Cambridge on 1 July, 1972. Their daughter Theresa was born in Glasgow, and sons Martin and Russell followed in 1975 and 1984, respectively.

Throughout his academic career, Bob displayed (though not ostentatiously) a broad and growing range of mathematical interests, most having some impact on number theory. After his initial work on the elementary and analytic theory, he added acquaintance with the algebraic side and was particularly fond of Galois theory. Then there was algebraic geometry (particularly over finite fields), modular forms, harmonic analysis, representation theory, geometry and probability. It is recalled, for example, that his inaugural lecture for his chair at Exeter was on Monte Carlo methods. Much of his work involved asymptotic or uniform density. He made extensive use of the Čebotarev density theorem in deriving, for example, global norm density theorems. He was interested in dynamical systems, in particular, the iterates of transformations, and in later years on the Galois groups of iterates of polynomials. Even in his final period, he had in mind problems on additive polynomials and Drinfel'd modules, constructive Galois theory and quantitative Čebotarev density theorems for infinite extensions of number fields - though (in his own words) at any one time, some of these would be "gently simmering on a back burner".

Bob had a considerable knowledge of and respect for the great masters over a broad sweep of mathematics, as well as a detailed awareness of mathematical literature. This was often the basis for developing his own techniques, as well as providing assistance to others less well-informed. Indeed, he was always prepared to take time from his own 
researches to help others working on problems in different areas with advice, books, references, etc. He was perfectly willing to do this "for free", but a number of joint papers did arise from such collaborations. In return, it was occasionally helpful to him for you to be present with him while he teased out a problem on the blackboard, even if one felt unable to contribute much. On such occasions, once the thread of an argument was there, it was remarkable how rigorous and complete this preliminary working might be - all the necessary constraints would be in place. His first published paper (on Gauss sums modulo a composite prime power), involving elementary manipulations with $p$-adic expansions, is regarded as a remarkable result. For his first joint paper, Bob was the enthusiastic "midwife" (his description) bringing to fruition the applications of a simple trick. His later papers contain many powerful, incisive estimates and characterisations.

Bob's enjoyment of mathematics and fund of knowledge were inspirational. Even at undergraduate level, he was quite happy to teach courses over a broad spectrum, constantly thinking through each topic afresh. Whether he was tutoring or lecturing to a group of undergraduates or speaking at a research meeting or seminar, he always wanted to engage with his audience from a point at which they could understand. So his presentations possessed both clarity and spontaneity. On the other hand, at talks given by others (whether lucid or dense), he was usually able to contribute to the discussion, be it question, observation, fact, reference, or anecdote.

While at Exeter and Glasgow Bob supervised a string of research students. He was invited to give lectures and courses in different places (including the Banach Centre, Warsaw; ETH (Zurich), and lecture tours in Germany and India). He persuaded the prestigious French Journées Arithmétique that Exeter was in France and organised their 1980 meeting there. He was a member of the mathematical societies of several countries, and, at various times, served on the editorial boards of a number of journals, including, of course, the Glasgow Mathematical Journal. Latterly, he acted as President of the Mathematical Section of the British Association (for communicating science). He played a full part in the normal scholarly activities of refereeing, reviewing and assessing. So, not only was Bob familiar with a wide range of mathematics, he also possessed a store of knowledge of its personnel, both historical and contemporary. He became well known and held in high esteem by many in the mathematical community. At conferences and meetings, he was a great companion at the more convivial sessions in restaurants or bars. Loosened up of an evening, he could discourse with authority on aspects of applied mathematics in a manner that could enlighten even experts.

Of course, Robert's family had to endure his "purple patches" when his research would take precedence over everything (working all night!) but he did have many other interests. From his father he inherited a lifelong passion for and detailed knowledge of steam trains. In his young days he enjoyed playing cricket - until this activity threatened to interfere with his research. Many weekends he went out walking in different parts of the country, chiefly with Josie but sometimes with other companions. He had a great interest in music - especially opera. He was a fluent reader of several European languages, in particular, Russian. Thus he was in demand as a reviewer of papers in Russian and translated a number of articles.

Robert and Josie and the family were separated for another short period in 1989 as he worked out his notice in Exeter while she came to Glasgow to see the children established in school. In Glasgow, Josie obtained a job with the British Council. In 1995, Bob and Josie nobly performed a valuable service for an international conference (for which I was chief organiser) by systematically patronising over a period (at their 
own expense!) most of the eating places near the university researching a guide to help conference participants enjoy their week in Glasgow. Later that year, she faced redundancy unless she moved to Manchester. So they decided to relocate the family: Robert would continue to live in Glasgow during term but would "go home" for vacations and occasional weekends. Their walks would now be in places like the Pennines instead of Scotland.

Three months later Robert caught what seemed to be flu. Yet it persisted with increasing breathlessness and weakness that resisted diagnosis and was not relieved by medication. In July 1996 he reported to the doctor's surgery in Glasgow and was taken to hospital where he was found to be suffering from heart failure. So an eagerlyanticipated sabbatical in Australia over 1996-97 was translated to a convalescence in Manchester. Physically, the remaining years were ones of considerable difficulty and distress, with continual problems of diagnosis and treatment, resulting in complications (including kidney failure) and delays. There were periods when he continued at work in Glasgow, and there were relapses which came to occur more frequently. In 2001 he began to be considered for a heart transplant. At this stage, early retirement became inevitable and became operative at the end of November 2001. Robert bore much pain with courage and equanimity. He continued to think about mathematics, though perhaps with less clarity and was not always able to complete projects that he undertook. Still, the Editor-in-Chief of this Journal recalls visiting him in hospital while undergoing the discomfort of kidney dialysis. Bob picked up a text at the bedside and proceeded to give a mini-lecture on Drinfel'd modules. When his family came to help him clear his office in Glasgow, Bob was concerned to be able to rescue what resources he felt needful.

There were many days when, in weakness, he was indebted to family members for nursing care. Yet there were brighter periods, good days when he could do more. Robert and Josie were able to visit family in Cyprus in April 2002 and take a short break to Prague (a city they had both always wanted to visit) in June. Josie writes, "In spite of his illness, Robert managed to drag me on foot for miles." On 1 July, they celebrated their 30th wedding anniversary and on 14 July his 55th birthday. From mid-2001 he had accepted the limitations of his situation and looked forward to the day a new heart would enable him to resume his research. It was not to be: medication for treating a complication raised blood pressure, and on 28 July, 2002, an aneurysm burst and he died immediately.

Bob Odoni might be regarded as the archetypal mathematician: as such he was absorbed, probing, scrupulous, rigorous, but also amiable, open and generous-spirited. Other matters (such as administration) were attended to but invariably held at a lower level. His dedication was noted even by those who were not mathematicians with mingled acceptance and curiosity. A friend writes, "In Italian cafe or real ale pub he would often be seen sitting quietly in a corner working or re-working equations or approaches to a problem with an intensity that risked the coffee growing cold or the beer flat. The friends he made in these places, as elsewhere, came to recognise when he did not wish to be disturbed. A degree of focus and concentration communicated itself in subtle ways: a pursing of the lips, the arching of eyebrows the furrowing of a forehead, the pace and intensity of writing. Nevertheless, Robert in the midst of even such concentration could register the arrival of a friend and would happily socialise at a convenient point." Certainly, there would be many number-theoretical problems that Bob would love to have solved. But I reckon there was no overarching goal no personal "Fermat's Last Theorem" - that was for him to resolve. So perhaps it 
is not really important that there were uncompleted fragments on his desk at the end - and no paper to crown his latter day enthusiasm for Drinfel'd modules. To us, his contribution was far more than the sum of his published papers. For him, it was sufficient to have been engaged so enjoyably in the magical, soothing, tantalising business of mathematics.

ACKNOWLEDGMENTS. I am extremely grateful to Josie Odoni for providing biographical details and sharing personal memories at such a time of loss. I would also thank other unnamed friends and colleagues who sent their own tributes. Some will recognise allusions to their contributions in the article and these are sincerely acknowledged here.

Stephen D. Cohen

\section{PUBLICATIONS OF R. W. K. ODONI}

1. On Gauss sums $\bmod p^{n}, n \geq 2$, Bull. London Math. Soc. 5 (1973), 325-327.

2. The statistics of Weil's trigonometric sums, Proc. Cambridge Philos. Soc. 74 (1973), 467-471. 169.

3. The Farey density of norm subgroups of global fields, I, Mathematika 20 (1973), 155

4. (with S. D. Cohen and W. W. Stothers) On the least primitive root modulo $p^{2}$, Bull. London Math. Soc. 6 (1974), 42-46. 200.

5. Multiplicative forms and associative algebras, J. London Math. Soc. (2) 8 (1974), 198 $60-62$.

6. A characterization of determinants over topological fields, Glasgow Math. J. 15 (1974),

7. Multiplicative forms and nonassociative algebras, Glasgow Math. J. 15 (1974), 129-130.

8. On norms of integers in a full module of an algebraic number field and the distribution of values of binary integral quadratic forms, Mathematika 22 (1975), 108-111.

9. On the norms of algebraic integers, Mathematika 22 (1975), 71-80.

10. On a problem of Narkiewicz, J. Reine Angew. Math. 288 (1976), 160-167.

11. Character sums over certain semigroups, Period. Math. Hungar. 7 (1976), 219-221.

12. (with S. D. Cohen) The Farey density of norm subgroups of global fields, II, Glasgow Math. J. 18 (1977), 57-67.

13. A new equidistribution property of norms of ideals in given classes, Acta Arith. 33 (1977), 53-63.

14. Some global norm density results obtained from an extended Čebotarev density theorem, Algebraic number fields: L-functions and Galois properties (Proc. Sympos., Univ. Durham, Durham, 1975), pp. 485-495. Academic Press, London, 1977.

15. (with Sunder Lal and R. L. McFarland) On $\alpha^{2}+\beta^{2}=p^{t}$ in certain cyclotomic fields, Number theory and algebra, pp. 195-197. Academic Press, New York, 1977.

16. Representations of algebraic integers by binary quadratic forms and norm forms from full modules of extension fields, J. Number Theory 10 (1978), 324-333.

17. A proof by classical methods of a result of Ax on polynomial congruences modulo a prime, Bull. London Math. Soc. 11 (1979), 55-58.

18. The distribution of integral and prime-integral values of systems of full-norm polynomials and affine-decomposable polynomials, Mathematika 26 (1979), 80-87.

19. A conjecture of Krishnamurthy on decimal periods and some allied problems, J. Number Theory 13 (1981), 303-319.

20. A problem of Erdös on sums of two squarefull numbers, Acta Arith. 39 (1981), 145-162.

21. Some remarks on the values taken by abelian group determinants, Linear and Multilinear Algebra 14 (1983), 297-303. 
22. Some relations connecting measures of convergence for series with nonincreasing terms, Mathematika 31 (1984), 17-24.

23. Scalar products of certain Hecke $L$-series and moments of weighted norm-counting functions, Canad. Math. Bull. 28 (1985), 272-279.

24. (with V. Varadharajan) Extension of RSA cryptosystems to matrix rings, Cryptologia 9 (1985), 140-153.

25. Trigonometric sums of Heilbronn's type, Math. Proc. Cambridge Philos. Soc. 98 (1985), 389-396.

26. On the prime divisors of the sequence $w_{n+1}=1+w_{1}+\cdots+w_{n}$, J. London Math. Soc. (2) 32 (1985), 1-11.

27. The Galois theory of iterates and composites of polynomials, Proc. London Math. Soc. (3) 51 (1985), 385-414.

28. Notes on the method of Frobenian functions with applications to Fourier coefficients of modular forms Elementary and analytic theory of numbers (Warsaw, 1982), 371-403, Banach Center Publ., 17, PWN, Warsaw, 1985.

29. A note on trigonometric sums in several variables, Math. Proc. Cambridge Philos. Soc. 99 (1986), 189-193.

30. An application of the $S$-unit theorem to modular forms on $\Gamma_{0}(N)$ New advances in transcendence theory (Durham, 1986), 270-279, Cambridge Univ. Press, Cambridge, 1988.

31. (with A. Greaves) Weil-numbers and CM-fields, I, J. Reine Angew. Math. 391 (1988), $198-212$.

32. Realising wreath products of cyclic groups as Galois groups, Mathematika 35 (1988), $101-113$.

33. (with J. E. Cremona) Some density results for negative Pell equations; an application of graph theory, J. London Math. Soc. (2) 39 (1989), 16-28.

34. On the distribution of norms of ideals in given ray-classes and the theory of central ray-class fields, Acta Arith. 52 (1989), 373-397.

35. (with J. E. Cremona) A generalization of a result of Iwasawa on the capitulation problem, Math. Proc. Cambridge Philos. Soc. 107 (1990), 1-3.

36. (with A. E. Stratton) Structure of Bernstein algebras, Algèbres génétiques (Montpellier, 1985), 117-125, Cahiers Math. Montpellier, 38, Univ. Sci. Tech. Languedoc, Montpellier, 1989.

37. A note on a recent paper of Iwasawa on the capitulation problem, Proc. Japan Acad. Ser. A Math. Sci. 65 (1989), 180-182.

38. (with S. D. Cohen) Galois groups associated with $C M$-fields, skew-symmetric matrices and orthogonal matrices, Glasgow Math. J. 32 (1990), 35-46.

39. On the number of integral ideals of given norm and ray-class. Mathematika 38 (1991), $185-190$.

40. Weil numbers and CM fields, II, J. Number Theory 38 (1991), 366-377.

41. A problem of Rankin on sums of powers of cusp-form coefficients, J. London Math. Soc. (2) 44 (1991), 203-217.

42. (with A. W. Mason and W. W. Stothers) Almost all Bianchi groups have free, noncyclic quotients, Math. Proc. Cambridge Philos. Soc. 111 (1992), 1-6.

43. Zeros of random polynomials over finite fields, Math. Proc. Cambridge Philos. Soc. 111 (1992), 193-197.

44. The spatial distribution of algebraic integers on constant-norm hypersurfaces, Mathematika 39 (1992), 350-366.

45. (with D. L. Johnson) Some results on symmetrically-presented groups, Proc. Edinburgh Math. Soc. (2) 37 (1994), 227-237.

46. (with A. W. Mason) Free quotients of subgroups of the Bianchi groups whose kernels contain many elementary matrices, Math. Proc. Cambridge Philos. Soc. 116 (1994), 253-273.

47. (with I. Anderson and N. J. Finizio) Character sums and $Z$-cyclic whist tournaments, Proceedings of the Twenty-fifth Southeastern International Conference on Combinatorics, Graph Theory and Computing (Boca Raton, FL, 1994). Congr. Numer. 100 (1994), 65-72.

48. (with P. G. Spain) Equidistribution of values of rational functions $(\bmod p)$, Proc. Roy. Soc. Edinburgh Sect. A 125 (1995), 911-929.

49. (with A. W. Mason) Non-normal, standard subgroups of the Bianchi groups, Proc. Amer. Math. Soc. 124 (1996), 721-726. 
50. On the Galois groups of iterated generic additive polynomials, Math. Proc. Cambridge Philos. Soc. 121 (1997), 1-6.

51. (with A. W. Mason) Ideal class groups of Dedekind domains contained in function fields, Proc. Roy. Irish Acad. Sect. A 97 (1997), 155-162.

52. Some Diophantine problems arising from the theory of cyclically-presented groups, Glasgow Math. J. 41 (1999), 157-165.

53. On additive polynomials over a finite field, Proc. Edinburgh Math. Soc. (2) 42 (1999), $1-16$.

54. Solution of a generalised version of a problem of Rankin on sums of powers of cuspform coefficients, Acta Arith. 104 (2002), 201-223. 